\title{
Layered Nano-Sheets: Synthesis and Applications
}

\author{
Muralidharan Paramsothy \\ NanoWorld Innovations (NWI), 1 Jalan Mawar, Singapore 368931, Singapore; mpsothy@yahoo.co.uk
}

Received: 2 March 2020; Accepted: 11 March 2020; Published: 12 March 2020

Extraordinary physical and chemical properties are enabled by two dimensional (2D) anisotropy and confinement effects in layered nano-sheet materials. Layered nano-sheet materials are 2D crystals possessing properties useful in applications ranging from electronics and energy storage to structural loads bearing nanocomposites. Thematically, six representative articles [1-6] have been published in this Special Issue:

Gao et al. [1] reported that low-temperature nitrogen plasma processing was conducted to modify graphitic carbon nitride $\left(\mathrm{g}-\mathrm{C}_{3} \mathrm{~N}_{4}\right)$ to enhance electro-catalytic performance for the hydrogen evolution reaction (HER). The plasma incorporated nitrogen atoms onto the surface of $\mathrm{g}^{-} \mathrm{C}_{3} \mathrm{~N}_{4}$. The modification improved surface hydrophilicity, electro-catalytic HER activity, and overall stability in HER after 2000 cycles. In the work by Zhao et al. [2], various ions including $\mathrm{H}_{3} \mathrm{O}^{+}, \mathrm{Fe}^{3+}, \mathrm{Au}^{3+}$, and $\mathrm{Zn}^{2+}$ were successfully encapsulated in graphene oxide nanoscrolls (GONSs). As the $\mathrm{pH}$ of the graphene oxide (GO) solution decreased from 5 to 0.15 , the height of GONS was increased from 50 to $190 \mathrm{~nm}$ due to increased interlayer distance by encapsulating $\mathrm{H}_{3} \mathrm{O}^{+}$. GONSs with encapsulated metal ions were prepared by dissolving metal ions into a $\mathrm{GO}$ solution with a $\mathrm{pH}$ of 0.3 . As-encapsulated metal ions were converted to metal or metal oxide nanoparticles when they were annealed at $480^{\circ} \mathrm{C}$ for $30 \mathrm{~min}$. By reducing $\mathrm{GO}$ to $\mathrm{rGO}$ with L-ascorbic acid in solution, $\mathrm{H}_{3} \mathrm{O}^{+}$embedded $\mathrm{rGONS}$ were fabricated by molecular combing $\mathrm{rGO}$ solution with a $\mathrm{pH}$ of 0.3 . The resistance-type pressure sensor based on the $(\mathrm{rGONS})_{0.3}$ mesh showed good response to applied pressure on it compared to that of the sensor based on (rGONS) $)_{5}$ mesh without $\mathrm{H}_{3} \mathrm{O}^{+}$.

As reported by Gill-Castell et al. [3], functionalized nanofibrous membranes based on poly(vinyl alcohol) (PVA) or sulfonated poly(vinyl alcohol) (SPVA) combined with graphene oxide (GO) were developed by means of electrospinning. The subsequent crosslinking reaction with sulfosuccinic acid (SSA) brought thermal and hydrothermal stability as well as the required electrical insulator performance and proton conductivity to the nanofibers. The crosslinked nanofibrous membranes were stable during simulated service conditions. Although fiber diameter increased after immersion, the presence of GO and the use of SPVA contributed to higher diameter stability. The developed nanofibrous composite membranes were considered for ionic multi-layered polyelectrolyte application. Saeed et al. [4] reported that graphene nanoplatelets were functionalized following an oxidation-reduction process, and then dispersed in glycol as the base fluid. The characterization of the thermo-physical properties of these nanofluids was performed by determining their viscosity and thermal conductivity due to the relevant impact on practical applications related with fluid flow and heat transfer. The effects of temperature and shearing time on viscosity were analyzed. Shear-thinning behaviour strongly influenced by temperature was exhibited.

In the work by Burguete et al. [5] for open technological application, a simple and reproducible method for the direct preparation of high purity silica-based micro/nanocharges was designed. The "modified atrane route" enabled a wide family of layered mesostructured silica derivatives to be obtained. Chemical homogeneity and good dispersion of the inorganic/organic functional groups was observed in the surfactant-assisted mesostructure formation. The main advantage of the resulting neutral-amine templated matrices (with regard to other natural or synthetic lamellar solids) was 
the ease of manufacture, modification, expansion, and adaptation to polymers, relevant to single one-pot procedures.

Lv et al.'s [6] work involved graphene oxide (GO) nanosheets prepared using the Hummers method, which were found to easily aggregate in aqueous and cement composites. Using carboxymethyl chitosan (CCS) as a dispersant, few-layered GO nanosheets (1-2 layers) were obtained by forming $\mathrm{CCS} / \mathrm{GO}$ intercalation composites. The testing results indicated that the few-layered GO nanosheets could uniformly spread in both aqueous and cement composites. A special feature was determined, namely that the microstructures consisted of regular-shaped crystals created by self-crosslinking. X-ray diffraction (XRD) results indicated that there was a higher number of cement hydration crystals in the GO/cement composites. It was also observed that partially-amorphous calcium-silicate-hydrate (C-S-H) gel turned into monoclinic crystals. Durability parameters such as penetration, freeze-thaw, carbonation, drying-shrinkage value, and pore structure showed marked improvement. The results indicated that it is possible to obtain cement composites with a compact microstructure and high structural load bearing performance by introducing CCS/GO intercalation composites.

Note: Bold italics highlight contemporary technological applications.

Acknowledgments: The Guest Editor thanks all the authors for submitting their work to the Special Issue and for its successful completion. A very important thank you to all the reviewers participating in the peer review process and enhancing the quality and impact of the manuscripts. On a vital note, a heartfelt expression of appreciation to Alisa Zhai, Tina Tian, and the editorial assistants who made the entire Special Issue creation a memorable experience. Thank you.

Conflicts of Interest: There are no conflicts of interest.

\section{References}

1. Gao, M.; Liu, D.; Yang, H.; Huang, H.; Luo, Q.; Huang, Y.; Yu, X.-F.; Chu, P.K. Modification of Layered Graphitic Carbon Nitride by Nitrogen Plasma for Improved Electrocatalytic Hydrogen Evolution. Nanomaterials 2019, 9, 568. [CrossRef] [PubMed]

2. Zhao, W.; Wang, L.; Pei, C.; Wei, C.; You, H.; Zhang, J.; Li, H. Impact of pH on Regulating Ion Encapsulation of Graphene Oxide Nanoscroll for Pressure Sensing. Nanomaterials 2019, 9, 548. [CrossRef] [PubMed]

3. Gil-Castell, O.; Galindo-Alfaro, D.; Sanchez-Ballester, S.; Teruel-Juanes, R.; Badia, J.D.; Ribes-Greus, A. Crosslinked Sulfonated Poly(vinyl alcohol)/Graphene Oxide Electrospun Nanofibers as Polyelectrolytes. Nanomaterials 2019, 9, 397. [CrossRef] [PubMed]

4. Saeed, E.; Pineiro, M.M.; Hermida-Merino, C.; Pastoriza-Gallego, M.J. Determination of Transport Properties of Glycol-Based NanoFluids Derived from Surface Functionalized Graphene. Nanomaterials 2019, 9, 252. [CrossRef] [PubMed]

5. Berguete, P.; Morales, J.M.; Fernandez, L.; Haskouri, J.E.; Latorre, J.; Guillem, C.; Perez-Pla, F.; Cros, A.; Beltran, D.; Beltran, A.; et al. Layered-Expanded Mesostructured Silicas: Generalized Synthesis and Functionalization. Nanomaterials 2018, 8, 817. [CrossRef] [PubMed]

6. Lv, S.; Hu, H.; Zhang, J.; Luo, X.; Lei, Y.; Sun, L. Fabrication of GO/Cement Composites by Incorporation of Few-Layered GO Nanosheets and Characterization of Their Crystal/Chemical Structure and Properties. Nanomaterials 2017, 7, 457. [CrossRef] [PubMed] 